\title{
PROTEÇÃO DA SAÚDE DO TRABALHADOR MEDIANTE TUTELA JURISDICIONAL ESPECÍFICA: A CONCRETIZAÇÃO DO DIREITO SOCIAL FUNDAMENTAL À PREVENÇÃO DOS INFORTÚNIOS LABORAIS
}

\author{
Aline Carneiro Magalhães \\ Gisele Silami Magalhães
}

ISSUE DOI: $10.21207 / 1983.4225 .238$

\section{RESUMO}

Este artigo propõe uma reflexão sobre a efetividade do direito social fundamental à prevenção e redução dos riscos inerentes ao trabalho. Parte da análise histórica e estatística dos acidentes laborais e examina o conteúdo do direito à saúde do trabalhador na ordem jurídica brasileira. Tem como objetivo demonstrar a necessidade de implementação do padrão prevencionista dos riscos ambientais e a adequação do uso da tutela jurisdicional específica para esse fim.

Palavras-chave: Acidentes do trabalho. Prevenção. Tutela específica. 


\section{INTRODUÇÃO}

Desde o momento histórico caracterizado pelo nascimento e incremento da industrialização, a problemática relacionada à saúde e à segurança no trabalho permeia as relações entre empregado e empregador. Apesar da alarmante e crescente ocorrência dos infortúnios no ambiente laboral, a conscientização da sociedade sobre a necessidade de adotar uma postura de prevenção vem sendo gradual.

A busca dos empregados por melhores condições de trabalhado e a consolidação dos direitos sociais na ordem jurídica, aliadas à conduta ativa do Estado na sua promoção, são fatores que contribuem continuamente para o desenvolvimento de um padrão comportamental sensível a essa realidade.

Esse estado de coisas motivou a consagração, em âmbito constitucional, do direito social fundamental à prevenção dos riscos inerentes ao trabalho, cuja compreensão se harmoniza com as normas, também constitucionais, de proteção ao meio ambiente, no qual se inclui o meio ambiente laboral. Trata-se de direitos fundamentados nos princípios cardeais da ordem constitucional, como a dignidade da pessoa humana e o valor social do trabalho.

A efetividade do direito à implementação do padrão prevencionista encontra no instrumento processual da tutela específica e inibitória um grande aliado. $\mathrm{O}$ caráter extrapatrimonial do direito à saúde e à segurança do trabalhador não condiz com a tutela ressarcitória padrão, centrada no pagamento de adicionais pelo labor em condições inadequadas ou de indenizações por lesões já consolidadas.

Urge a prática de uma prestação jurisdicional hábil a compelir e promover, no âmbito das empresas, a adoção de medidas voltadas à redução dos riscos ambientais. O objetivo deste artigo é demonstrar que o Poder Judiciário e os agentes do processo podem e devem atuar nesse sentido, fazendo uso da tutela específica das obrigações de fazer consistentes na extinção ou redução máxima dos riscos inerentes ao meio ambiente do trabalho.

Este trabalho parte da análise de dados históricos e estatísticos sobre os infortúnios laborais, demonstrando a gravidade da realidade brasileira. Em seguida, examina o tratamento conferido à saúde do trabalhador no ordenamento jurídico pátrio, ressaltando a importância legal dada ao tema. No tópico subsequente, trata do direito à prevenção como direito social fundamental e da necessidade da sua efetivação. Ao final, analisa as 
normas processuais sobre a tutela específica, importante instrumento processual capaz de dar concretude ao padrão prevencionista constitucionalmente garantido.

\section{DADOS GERAIS SOBRE A INFORTUNÍSTICA LABORAL: ANÁLISE HISTÓRICA E ESTATÍSTICA}

A questão dos infortúnios laborais não é nova, estando diretamente ligada à Revolução Industrial ocorrida na Europa no século XVIII. A partir desse momento histórico, foi possível observar inúmeras transformações na sociedade, como a construção e consolidação do sistema capitalista, os avanços tecnológicos, o incremento da industrialização e as mudanças nas relações intersubjetivas. Nasceu ali a figura do trabalhador e do empregador, ligados por interesses recíprocos, na medida em que, enquanto o obreiro necessitava do trabalho para prover o sustento próprio e o de sua família, o empregador necessitava de mão de obra para viabilizar seus ganhos.

Entretanto, essa relação nunca foi equilibrada e a gana pela maximização dos lucros fez com que o empregador buscasse seu objetivo, muitas vezes, à custa da saúde, integridade e vida dos obreiros. O ambiente laboral era extremamente insalubre e perigoso, sendo a rotina nas fábricas marcada por inúmeros acidentes, condições de trabalho precárias e toda a forma de desrespeito ao trabalhador que laborava em jornadas extenuantes, mediante uma remuneração que mal lhe permitia alimentar. ${ }^{1}$

Essa realidade se desenvolveu sob o signo do Estado Liberal, caracterizado pelo individualismo, não intervenção estatal, busca incessante por lucros, abstração da questão social e grande desigualdade entre muitos que viviam na pobreza e um pequeno grupo que gozava dos ganhos auferidos com o novo sistema. Esse modelo perdurou por longos anos e rendeu, entre outras consequências, um quadro de grandes mazelas para a maior parte da população.

O cenário somente passou a ser objeto de mudanças quando, de um lado, os trabalhadores começaram a se unir e a reivindicar condições de vida mais dignas (em especial, condições ligadas ao meio ambiente do

\footnotetext{
${ }^{1}$ O Filme "Daens: um grito de Justiça" retrata bem esse contexto no final do século XIX na Bélgica.
} 
trabalho) e, de outro, os governantes passaram a se conscientizar da necessidade de intervenção na sociedade. $\mathrm{O}$ Estado adotou uma postura mais ativa, buscando promover melhor distribuição de renda, assistência, acesso à saúde e educação, direitos trabalhistas e previdenciários.

Nesse contexto, também os valores da sociedade foram paulatinamente se alterando, com a ascensão de direitos imateriais em relação aos patrimoniais. $\mathrm{O}$ homem agora passa a ser o centro do ordenamento jurídico e a promoção de sua dignidade ganha contornos de direito fundamental. Segundo Gabriel Saad:

$\mathrm{O}$ direito à vida e à integridade psicofísica se sobrepõem ao direito de defesa ou ao direito de propriedade de que é titular o empresário, porque não resta dúvida de que a vida do trabalhador prevalece sobre qualquer interesse material ou econômico da empresa. $^{2}$.

Com o tempo, avanço e aprimoramento das legislações e dos valores escolhidos pelo homem como mais relevantes, a questão acerca da saúde e segurança do trabalhador ganhou novos contornos, passando a sociedade a se ocupar com esta temática. ${ }^{3}$

Apesar dos progressos observados ao longo dos anos, as estatísticas demonstram que os números dos acidentes de trabalho ainda são elevados e que, a cada minuto, muitos trabalhadores deixam de exercer o seu

\footnotetext{
${ }^{2}$ SAAD, E. Gabriel. Curso de Direito do Trabalho. São Paulo: LTr, 2000. p. 318.

${ }^{3}$ De acordo com Sebastião Geraldo Oliveira (2009) a questão dos acidentes do trabalho que, no Brasil, até 1850 não tinha qualquer amparo legal, foi, aos poucos, passando a fazer parte do ordenamento jurídico. O Decreto Legislativo n. 3.724 de 15/01/1919 foi considerado a primeira lei acidentária pátria. Hoje, vigora a Lei n. 8.213, de 24/07/1991, estando os aspectos centrais do acidente do trabalho disciplinados nos artigos 19 a 23. No que tange a responsabilidade civil do empregador pelos infortúnios laborais, as fontes normativas são o artigo $7^{\circ}$, inciso XXVIII, da CR/88 e artigo 927, § único, do CC/02.
} 
labor em face de infortúnios que poderiam ser evitados, pois, "a experiência demonstra que a maior parte destes acidentes são previsíveis.". ${ }^{4}$ As estatísticas ainda demonstram que o Brasil ocupa hoje o quarto lugar na lista de países com maior número de acidentes do trabalho. ${ }^{5}$

Dados da OIT divulgados em 1985 informavam que, a cada três minutos, um trabalhador perdia a vida em consequência de acidente do trabalho ou doença ocupacional e que, a cada segundo pelo menos, quatro trabalhadores sofriam algum tipo de lesão. ${ }^{6}$

Assevera Süssekind, com base em dados da Previdência Social, que, em 2002, ocorreram 387.905 acidentes de trabalho, sendo 46.621 a caminho do trabalho, 2.898 mortes de acidentados, 20.886 casos de doenças profissionais e 15.029 de invalidez permanente. ${ }^{7}$

De 2002 a 2007, "a quantidade de acidentes voltou a subir de forma acentuada e sistemática (92\%), deixando mais evidente a necessidade de adoção de medidas legais e governamentais urgentes para tentar reverter essa nova tendência". Em 2007, por dia, 31 trabalhadores deixaram o mundo do trabalho, quer em razão da morte por acidente de trabalho (8 óbitos por dia), quer em razão da aposentadoria por incapacidade permanente, além de uma média de 772 trabalhadores que entraram em gozo de auxílio-doença acidentário com afastamento por mais de 15 dias. ${ }^{8}$

Dados estatísticos do INSS apontam que, no Brasil, em 2009, ocorreu cerca de uma morte a cada 3,5 horas, motivada pelo risco decorrente dos fatores ambientais do trabalho. Por volta de 83 acidentes e doenças do trabalho foram reconhecidos a cada uma hora na jornada diária. No mesmo ano, por dia, em torno de 43 trabalhadores não retornaram ao trabalho devido à invalidez ou morte e os benefícios pagos pelo governo a esse título chegaram a 14 bilhões. ${ }^{9}$

\footnotetext{
${ }^{4}$ OLIVEIRA, Sebastião Geraldo de. Indenizações por acidente do trabalho ou doença ocupacional. 5. ed. (rev., ampl. e atual.). São Paulo: LTr, 2009. p. 30.

${ }^{5}$ De acordo com Sebastião Geraldo de Oliveira, o Brasil só perde para China, Índia e Estados Unidos. (Dado informado na palestra sobre "Política Nacional de Segurança e Saúde no Trabalho", proferida no dia 27 de abril de 2012, no I Seminário de Prevenção de Acidentes de Trabalho promovido pelo TRT da $3^{\text {a }}$ Região).

${ }^{6}$ Idem. p. 29.

${ }^{7}$ SUSSEKIND, Arnaldo. Instituições de Direito do Trabalho. Vol. II. 22. ed. (atual. por Arnaldo Sussekind e João de Lima Teixeira Filho). São Paulo: LTr, 2005. p. 927.

${ }^{8}$ OLIVEIRA, Sebastião Geraldo de. Indenizações por acidente do trabalho ou doença ocupacional. 5. ed. (rev., ampl. e atual.). São Paulo: LTr, 2009. p. 13.

9 BRASIL. Tribunal Superior do Trabalho. Disponível em: <http://www.tst.jus.br/ prevencao/ /noticia2.html>. Acesso em: 05/11/2011.
} 
Ainda de acordo com dados da Previdência Social, em 2010, ocorreram 701.496 acidentes do trabalho, dos quais resultaram 2.712 óbitos (aproximadamente 7 por dia) e 14.097 vítimas com incapacidade permanente (em torno de 38 pessoas por dia), sendo jovens de 25 a 29 anos os maiores atingidos, ou seja, aqueles que estão iniciando e consolidando sua vida profissional. ${ }^{10}$

Estes números demonstram que, ainda no contexto atual, em meio a tanta modernidade e sofisticação, com a possibilidade de pessoas se conectarem a outras em diferentes partes do mundo em tempo real, com a existência de maquinário de última geração, com pesquisas e avanços tecnológicos em diversos setores da atividade econômica, os acidentes do trabalhado continuam ocorrendo em grande escala, causando deletérios efeitos em toda a sociedade.

Sob o aspecto social, é inadmissível que o trabalho - fonte de realização pessoal, material e profissional e meio de sustento - seja sinônimo de sofrimento, danos e mazelas. ${ }^{11}$ Sob o aspecto econômico, bilhões são gastos em decorrência do pagamento de benefícios previdenciários, além das constantes e elevadas quantias pagas a título de indenização pelos infortúnios perante a Justiça do Trabalho. Tudo passível de ser evitado a partir da concretização do direito social à prevenção.

Independente do enfoque analisado, os efeitos dos acidentes do trabalho são sentidos por toda a sociedade. A história e as estatísticas demonstram que, desde a Revolução Industrial até os dias atuais, os trabalhadores convivem diuturnamente com os infortúnios laborais. A despeito dos avanços observados, quer na postura dos cidadãos frente ao tema, quer sob o aspecto legislativo, ainda há muito por fazer para reverter este quadro, em especial no que tange à prevenção, pois muitos desses acidentes podem (e devem) ser evitados.

\footnotetext{
10 BRASIL. Anuário Estatístico da Previdência Social 2010. Disponível em: <http:// www.previdencia.gov.br/conteudoDinamico.php?id=1162>. Acesso em: 20/04/2012.

${ }^{11}$ Em palestra sobre "Política Nacional de Segurança e Saúde no Trabalho", proferida no dia 27 de abril de 2012 no I Seminário de Prevenção de Acidentes de Trabalho promovido

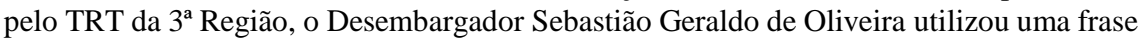
que, infelizmente, retrata o contexto atual acerca dos acidentes do trabalho: "O trabalhador sai de casa para ganhar a vida e encontra a morte."
} 


\section{O DIREITO À SAÚDE DO TRABALHADOR NA ORDEM JURÍDICA BRASILEIRA}

No ordenamento jurídico brasileiro, o direito à saúde se classifica como direito subjetivo público, exigível do Estado. A Constituição da República de 1988 (CR/88), em seu artigo 196, estabelece, categoricamente, que a saúde é direito de todos e dever do Estado. Trata-se de um direito social fundamental, de acesso universal e igualitário (artigo $6^{\circ}$ ). A teor do artigo 197, as normas relativas à saúde são de ordem pública, porquanto regulam um serviço público essencial. ${ }^{12}$

A exigibilidade do direito à saúde também é claramente depreendida dos artigos $2^{\circ}$ e $3^{\circ}$ da Lei 8.080/90, que dispõe sobre as condições para sua promoção, proteção e recuperação, bem como sobre a organização e o funcionamento dos serviços correspondentes. Segundo tais dispositivos, o Estado tem o dever de executar políticas públicas e oferecer condições de acesso universal e igualitário, mas o direito à saúde também tem eficácia entre particulares e pode ser exigido das pessoas, da família, das empresas e da sociedade.

Art. $2^{\circ}$ A saúde é um direito fundamental do ser humano, devendo o Estado prover as condições indispensáveis ao seu pleno exercício. $\S 1^{\circ} \mathrm{O}$ dever do Estado de garantir a saúde consiste na formulação e execução de políticas econômicas e sociais que visem à redução de riscos de doenças e de outros agravos e no estabelecimento de condições que assegurem acesso universal e igualitário às ações e aos serviços para a sua promoção, proteção e recuperação. $\S 2^{\circ} \mathrm{O}$ dever do Estado não exclui o das pessoas, da família, das empresas e da sociedade.

Art. $3^{\circ}$ A saúde tem como fatores determinantes e condicionantes, entre outros, a alimentação, a moradia, o saneamento básico, o meio ambiente, o trabalho, a renda, a educação, o transporte, o lazer e o acesso aos bens e serviços essenciais; os níveis de saúde da população expressam a organização social e econômica do País. Parágrafo único. Dizem respeito

12 OLIVEIRA, Sebastião Geraldo de. Indenizações por acidente do trabalho ou doença ocupacional. 5. ed. (rev., ampl. e atual.). São Paulo: LTr, 2009. p. 108-109. 
também à saúde as ações que, por força do disposto no artigo anterior, se destinam a garantir às pessoas e à coletividade condições de bem-estar físico, mental e social."

Essas disposições, por óbvio, aplicam-se à saúde do trabalhador - espécie da saúde genericamente considerada - aliando-se a outras normas que, apesar de dispersas em diversos instrumentos legais, formam um consistente sistema voltado à prevenção dos riscos ambientais e à promoção de condições dignas de trabalho.

$\mathrm{Na} \mathrm{CR} / 88$, o artigo $7^{\circ}$, inciso XXII, anuncia a norma de prevenção dos riscos laborais. $\mathrm{O}$ artigo 225 assegura a todos o direito ao meio ambiente ecologicamente equilibrado, bem de uso comum do povo e essencial à sadia qualidade de vida. E o artigo 200, em seu inciso VIII, atribui ao Sistema Único de Saúde o dever de colaborar na proteção do meio ambiente, compreendido o do trabalho.

No plano infraconstitucional, a Consolidação das Leis do Trabalho (CLT) contempla capítulo especialmente destinado às disposições sobre segurança e medicina do trabalho (Título I, Capítulo V, artigos 154 a 201). Outro importante núcleo normativo sobre o tema está nas Normas Regulamentadoras da Portaria n. 3.214/78 do Ministério do Trabalho e Emprego, por delegação normativa expressa do artigo 200 da CLT e outras leis ordinárias ${ }^{13}$.

A Lei 6.938/81 dispõe sobre a Política Nacional de Meio Ambiente. Embora sem mencionar expressamente o meio ambiente do trabalho, ela estende sua proteção aos casos de degradação da qualidade ambiental que prejudique ou coloque em risco a saúde, a vida e a integridade física dos trabalhadores - o que decorre da interpretação conforme os artigos 225 e 200, inciso VIII, da CR/88, dispositivos que representaram grande avanço no tocante à proteção do meio ambiente em nosso país ${ }^{14}$.

${ }^{13}$ Entre essas Normas Regulamentadoras, apresentam especial relevância as que dispõem sobre a implementação do SESMT - Serviços Especializados em Engenharia de Segurança e em Medina do Trabalho (NR-4), do PCMSO - Programa de Controle Médico de Saúde Ocupacional (NR-7) e do PPRA - Programa de Prevenção de Riscos Ambientais (NR-9), tendo em vista que se trata de medidas preventivas para a defesa do meio ambiente de trabalho.

${ }^{14}$ Segundo Raimundo Simão de Melo (2010, p. 46-47), deveriam ser mais seriamente observados e cumpridos os dispositivos que versam sobre a tutela penal do meio ambiente de trabalho. $\mathrm{O}$ artigo 132 do Código Penal criminaliza o ato daquele que expõe a vida ou a saúde de outrem a perigo direto e iminente. O artigo 15 da Lei 6.938/81 define como crime 
No plano internacional, o Brasil ratificou algumas Convenções da Organização Internacional do Trabalho (OIT) sobre saúde, higiene, segurança e meio ambiente laboral ${ }^{15}$. São exemplos relevantes a Convenção 148 , que dispõe sobre a proteção dos trabalhadores contra os riscos provenientes da contaminação do ar, do ruído e das vibrações no local de trabalho; a Convenção 155, que determina que o país adote uma política nacional em matéria de segurança, saúde dos trabalhadores e meio ambiente do trabalho; e a Convenção 161, que fixa orientações sobre a implantação de serviços de saúde no trabalho ${ }^{16}$.

Em 2006, a OIT aprovou a Convenção 187, com a ideia central de promover a melhoria contínua da segurança e da saúde no trabalho. A Convenção 187 visa à instituição de uma cultura de prevenção ininterrupta, de modo a reduzir sistematicamente as estatísticas acidentárias. Para tanto, o documento fixa ao país signatário uma linha básica de atuação:

a) elaborar uma política nacional sobre segurança e saúde no trabalho e no meio ambiente do trabalho (art. 3);

b) estabelecer, manter e desenvolver de forma progressiva, com reexame periódico, um sistema nacional de segurança e saúde no trabalho (art. 4);

a conduta do poluidor que expõe a perigo a incolumidade humana, animal ou vegetal, ou que torne mais grave a situação de perigo já existente. Mais aprimorada, a Lei 9.605/98 (Lei dos Crimes Ambientais) estabelece, no artigo $3^{\circ}$, a possibilidade de estender as sanções penais, civis e administrativas às pessoas jurídicas, quando o ato for praticado por decisão de seu representante legal ou contratual, ou de seu órgão colegiado, no interesse ou benefício da entidade.

15 As Convenções da OIT ratificadas pelo Brasil estão disponíveis em: < http://www.oit.org.br/convention>.

${ }^{16}$ Outras tratam de regimes de proteção em circunstâncias específicas de trabalho, como as Convenções 115 (proteção contra radiação ionizante), 127 (peso máximo das cargas), 134 (prevenção de acidentes dos marítimos), 136 (prevenção contra os riscos de intoxicação pelo benzeno), 139 (prevenção e controle de riscos profissionais causados pelas substâncias cancerígenas), 162 (utilização de asbesto com segurança), 163 (proteção da saúde e assistência médica de trabalhadores marítimos), 167 (segurança e saúde na construção), 170 (segurança na utilização de produtos químicos), 174 (prevenção de acidentes industriais maiores), 176 (segurança e saúde nas minas) e 184 (segurança e saúde na agricultura). 
c) elaborar, aplicar, controlar e reexaminar periodicamente um programa nacional de segurança e saúde no trabalho (art. 5). ${ }^{17}$

Mesmo sem a ratificação da Convenção 187, o Brasil tem avançado nessa linha de atuação. A Portaria Interministerial n. 152/2008 instituiu a Comissão Tripartite de Saúde e Segurança no Trabalho, com o objetivo de revisar e ampliar a Política Nacional de Segurança e Saúde do Trabalhador (PNSST), propor o aperfeiçoamento do Sistema Nacional de Segurança e Saúde no Trabalho e elaborar um Programa Nacional de Saúde e Segurança no Trabalho. Como resultado dessa iniciativa, a revisão da PNSST foi aprovada pelo Decreto 7.602, de 07/11/2011, com as seguintes diretrizes:

a) inclusão de todos trabalhadores brasileiros no sistema nacional de promoção e proteção da saúde;

b) harmonização da legislação e a articulação das ações de promoção, proteção, prevenção, assistência, reabilitação e reparação da saúde do trabalhador;

c) adoção de medidas especiais para atividades laborais de alto risco;

d) estruturação de rede integrada de informações em saúde do trabalhador;

e) promoção da implantação de sistemas e programas de gestão da segurança e saúde nos locais de trabalho; f) reestruturação da formação em saúde do trabalhador e em segurança no trabalho e o estímulo à capacitação e à educação continuada de trabalhadores;

g) promoção de agenda integrada de estudos e pesquisas em segurança e saúde no trabalho.

Estruturadas nesses moldes, as normas concernentes à saúde do trabalhador compõem um amplo sistema tendente à prevenção do risco e à promoção de condições dignas de trabalho. Oferecem base suficiente para

\footnotetext{
17 OLIVEIRA, Sebastião Geraldo de. Indenizações por acidente do trabalho ou doença ocupacional. 5. ed. (rev., ampl. e atual.). São Paulo: LTr, 2009. p. 87.
} 
a implementação do modelo prevencionista dos riscos ambientais, elevando-se a compreensão da saúde do trabalhador à acepção positiva de completo bem-estar físico, mental e social.

Segundo Oliveira, o maior desafio não é mais o reconhecimento do direito à saúde do trabalhador, já que as normas jurídicas são numerosas e suficientemente claras a proclamá-lo. Para ele é lamentável a abordagem jurisdicional do direito à saúde, em que a tutela ressarcitória venha prevalecendo sobre a concepção da prevenção dos riscos. E ressalta: "O progresso ocorrido no direito material necessita de instrumentos processuais adequados e nova postura das partes, advogados, membros do Ministério Público e juízes, para não haver embaraço no caminho já pavimentado do direito à saúde". ${ }^{18}$

\section{A PREVENÇÃO DOS ACIDENTES DE TRABALHO COMO DIREITO SOCIAL FUNDAMENTAL}

O Estado Liberal, fruto do Iluminismo e das Revoluções Liberais, caracterizou-se pela criação de normas que anunciavam a liberdade do homem perante o Estado, a igualdade formal entre os cidadãos e a supremacia da propriedade privada - os denominados direitos de liberdade ou direitos fundamentais de primeira geração, em sua maior parte elencados na Declaração dos Direitos do Homem e do Cidadão (1789).

Mais adiante, as distorções provenientes da política do laissezfaire levaram à crise do Estado Liberal abstencionista e à formação do Estado Social, marcado pelo papel mitigador dos conflitos sociais e promotor de políticas públicas, justiça e paz social. Foi a Constituição do México de 1917 a primeira a demonstrar preocupação com os problemas sociais, prevendo normas referentes à igualdade substancial, aos direitos trabalhistas e abolindo o caráter absoluto da propriedade privada. Em 1919, a Constituição alemã de Weimar trilhou o mesmo caminho, contemplando direitos sociais.

Estava, desse modo, estabelecido um novo modelo, que, seguido por diversos países, consagrava no âmbito legal o que foi denominado de direitos sociais ou direitos fundamentais de segunda geração.

\footnotetext{
${ }^{18}$ OLIVEIRA, Sebastião Geraldo de. Indenizações por acidente do trabalho ou doença ocupacional. 5. ed. (rev., ampl. e atual.). São Paulo: LTr, 2009. p. 416-417.
} 
Assim como os direitos de primeira geração, os direitos sociais têm como objeto a proteção do indivíduo, mas se diferenciam por atribuir ao cidadão o poder de exigir do Estado o cumprimento de prestações positivas. O Estado Social tem o dever de agir para promover o efetivo acesso do homem a direitos como educação, saúde, previdência, trabalho e lazer, que se realizam por meio de programas de ação do governo.

Nesse contexto, a propriedade precisa se submeter a uma função social; a liberdade contratual é mitigada por normas imperativas que ditam o contorno do pacto; a liberdade de expressão pressupõe uma formação intelectual decorrente do acesso à educação; a lei, em alguns casos, confere tratamento desigual para igualar, no plano jurídico, as desigualdades existentes no mundo dos fatos.

Percebe-se que a fruição dos direitos sociais possibilita a efetivação dos direitos individuais de primeira geração. Ou seja, o acesso a educação, saúde, direitos trabalhistas e previdência permite que a pessoa se desenvolva, possa criar uma consciência crítica e usufruir das liberdades preconizadas na lei. Sob essa perspectiva, há a noção de complementaridade dos direitos humanos.

O período de ascensão dos direitos sociais é marcado não só por sua constitucionalização, mas também por sua internacionalização, em especial com a criação da Organização Internacional do Trabalho (OIT), pessoa jurídica de Direito Internacional Público de caráter permanente, responsável pela proteção do trabalhador em nível mundial, mediante o estabelecimento de um padrão digno e humano de trabalho. De acordo com José Luiz Quadros (2000, p.31) “o Direito do Trabalho é o Direito Social por excelência". ${ }^{19}$

Segundo Ferreira Filho (2009), os direitos sociais foram consagrados em 1919 e reiterados após a $2^{\text {a }}$ Guerra Mundial, mas seu coroamento se deu com a Declaração Universal dos Direitos do Homem de 1948, em que os direitos fundamentais de primeira geração (as liberdades) e os de segunda geração (os direitos sociais) passaram a conviver lado a lado, de maneira harmônica e interdependente.

Os direitos fundamentais caracterizam-se como "os valores mais importantes da convivência humana, aqueles sem os quais as sociedades

${ }^{19}$ OLIVEIRA, Sebastião Geraldo de. Indenizações por acidente do trabalho ou doença ocupacional. 5. ed. (rev., ampl. e atual.). São Paulo: LTr, 2009. p. 416-417. 
acabam perecendo, fatalmente, por um processo irreversível de desagregação". ${ }^{20}$

Os direitos fundamentais estão ligados a valores escolhidos pelo homem, no decorrer da história, como imprescindíveis para a manutenção de uma vida minimamente digna. ${ }^{21}$ Traduzem os anseios maiores da sociedade em determinado momento do tempo, a partir do seu desenvolvimento social, econômico e político. As gerações de direitos fundamentais apresentam, como dito, uma relação de interdependência, formando um todo unitário, indivisível e que, por representar aquilo que é essencial para o ser humano, não pode ser renunciado, suprimido ou diminuído.

No plano interno, a CR/88 representou um marco na consagração dos direitos sociais: os direitos fundamentais de segunda geração.

O direito à prevenção dos infortúnios laborais está previsto no capítulo que trata dos direitos sociais, que, por sua vez, está inserido no título que elenca os direitos fundamentais. Donde se conclui ${ }^{22}$ que se trata de um direito fundamental de segunda geração, ou seja, direito social que visa permitir ao trabalhador gozar de uma vida saudável no ambiente de trabalho, em que haja respeito à sua integridade física e mental, saúde e dignidade.

A fundamentalidade do direito de redução dos riscos laborais se revela na mesma medida em que se constata ser a partir do trabalho, prestado à luz das normas trabalhistas e livre de infortúnios, que o homem tem condições de viver com dignidade, buscando uma existência melhor. Esse fim só é alcançado quando se está diante de um ambiente de trabalho seguro e saudável, que permita ao obreiro desenvolver seu labor diário livre da ameaça constante da ocorrência de infortúnios.

A definição do direito à prevenção dos acidentes tem estreita relação com o princípio da dignidade humana. $\mathrm{O}$ artigo $1^{\circ}$ da CR/88 estabelece que são fundamentos da República e do Estado Democrático de Direito, entre outros, a dignidade da pessoa humana e os valores sociais do trabalho. Essas dicções são complementadas pelo artigo 170, que, ao tratar

\footnotetext{
${ }^{20}$ COMPARATO, Fábio Konder. Afirmação histórica dos direitos humanos. 2. ed. (rev. e ampl.). São Paulo: Saraiva, 2001. p. 26.

${ }^{21}$ Segundo Alexandre de Moraes (1998, p.39), o conjunto institucionalizado de direitos e garantias do ser humano que tem por finalidade básica o respeito a sua dignidade, por meio de sua proteção contra o arbítrio do poder estatal e o estabelecimento de condições mínimas de vida e desenvolvimento da personalidade humana pode ser definido como direitos humanos fundamentais.

${ }^{22}$ Por meio da hermenêutica - técnica de interpretação das leis.
} 
da ordem econômica, determina que a livre iniciativa seja exercida nos limites impostos pela defesa do meio ambiente e pela valorização do trabalho humano, de modo a assegurar existência digna a todos, conforme os ditames da justiça social. ${ }^{23}$

Segundo Maria Celina Bodin de Moraes (2006, p. 118-119), a dignidade humana é o supraprincípio que confere unidade axiológica à ordem jurídica e deve ser aplicado na recriação dos institutos jurídicos: "será 'desumano', isto é, contrário à dignidade humana, tudo aquilo que puder reduzir a pessoa (o sujeito de direitos) à condição de objeto". Desse modo é que, fazendo opção axiológica pela dignidade da pessoa humana, a CR/88 enuncia a predominância das situações jurídicas existenciais sobre as patrimoniais:

(...) o atual ordenamento jurídico, em vigor desde a promulgação da Constituição Federal de 5 de outubro de 1988, garante tutela especial e privilegiada a toda e qualquer pessoa humana, em suas relações extrapatrimoniais, ao estabelecer como princípio fundamental, ao lado da soberania e da cidadania, a dignidade humana. Como regra geral daí decorrente, pode-se dizer que, em todas as relações privadas nas quais venha a ocorrer um conflito entre uma situação jurídica subjetiva existencial e uma situação jurídica patrimonial, a primeira deverá prevalecer, obedecidos, dessa forma, os princípios constitucionais que estabelecem a dignidade da pessoa humana como valor cardeal do sistema. (MORAES, 2006, p. 145)

Desse modo é que a CR/88 deixa assente o direcionamento para a implantação, em caráter prioritário, do padrão prevencionista dos riscos ambientais do trabalho como medida de saúde pública. $\mathrm{O}$ artigo $7^{\circ}$, em seu inciso XXII, ao estabelecer como direito dos trabalhadores a "redução dos

\footnotetext{
${ }^{23}$ MELO, Raimundo Simão de. Direito ambiental do trabalho e a saúde do trabalhador. 4. ed. São Paulo: LTr, 2010. p. 63.
} 
riscos inerentes ao trabalho por meio de normas de saúde, higiene e segurança", institui o princípio fundamental sobre a promoção de medidas preventivas nos locais de trabalho. ${ }^{24}$

Além de anunciar o princípio da prevenção em conotação programática, o inciso XXII do artigo $7^{\circ}$ da CR/88 também se reveste da força normativa própria dos direitos subjetivos ${ }^{25}$. Trata-se de um direito social fundamental ${ }^{26}$ a exigir a atuação positiva do Estado e dos indivíduos imbuídos do dever jurídico correspondente, de modo a alcançarem sua concretização na realidade dos trabalhadores brasileiros.

Na lição de Luís Roberto Barroso ${ }^{27}$, efetividade significa a eficácia social da norma, a realização do Direito, o desempenho concreto de sua função social: "Ela representa a materialização, no mundo dos fatos, dos preceitos legais e simboliza a aproximação, tão íntima quanto possível, entre o dever-ser normativo e o ser da realidade social". É esse desafio da efetividade que deve orientar a aplicação das normas sobre saúde do trabalhador e meio ambiente de trabalho.

Com o objetivo de conferir concretude ao direito de prevenção dos infortúnios laborais, ganha relevância o manejo da tutela específica e inibitória, instrumento processual voltado à tutela jurisdicional adequada dos direitos sociais - direitos que, por essência, não têm cunho patrimonial e, por essa razão, não se coadunam com a tutela ressarcitória na forma pecuniária. A tutela específica e inibitória tem caráter preventivo do dano e

\footnotetext{
${ }^{24}$ OLIVEIRA, Sebastião Geraldo de. Proteção jurídica à saúde do trabalhador. 5. ed. (rev., atual. e ampl.). São Paulo: LTr, 2010. p. 123.

${ }^{25} \mathrm{Na}$ sistematização proposta por Barroso (2007, p. 90), as normas constitucionais classificam-se em: normas constitucionais de organização (que têm por objeto organizar o exercício do poder político); normas constitucionais definidoras de direito (que têm por objeto fixar os direitos fundamentais dos indivíduos, quais sejam, os direitos políticos, individuais, sociais e difusos); e normas constitucionais programáticas (que têm por objeto traçar os fins públicos a serem alcançados pelo Estado.

${ }^{26}$ Sobre a fundamentalidade dos direitos sociais, adota-se como premissa a lição de Sarlet (2007, p. 329): “[...] firma-se aqui posição em torno da tese de que - pelo menos no âmbito do sistema de direito constitucional positivo nacional - todos os direitos sociais são fundamentais, tenham sido eles expressa ou implicitamente positivados, estejam eles sediados no Título II da CF (dos direitos e garantias fundamentais) ou dispersos pelo restante do texto constitucional ou mesmo que estejam (também expressa e/ou implicitamente) localizados nos tratados internacionais regularmente firmados e incorporados pelo Brasil".

${ }^{27}$ BARROSO, Luís Roberto. O direito constitucional e a efetividade de suas normas: limites e possibilidades da Constituição brasileira. 9. ed. Rio de Janeiro: Renovar, 2009. p. 82-83.
} 
tende a compelir o devedor ao adimplemento da obrigação in natura. Serve, assim, à concretização do direito social à prevenção.

\section{4}

\section{A TUTELA JURISDICIONAL ESPECÍFICA E A EFETIVIDADE DO DIREITO À PREVENÇÃO DOS RISCOS AMBIENTAIS E À SAÚDE DO TRABALHADOR}

$\mathrm{Na}$ análise histórica do Direito Processual, a segunda metade do século XX foi marcada pela transição entre o positivismo conceitualista e o instrumentalismo substancial. Essa transformação denotou a preocupação dos processualistas com a necessidade de tornar efetiva a tutela jurisdicional - ou, em outras palavras, com a necessidade de fazer com que, por meio do processo, os direitos materiais, em suas diversas categorias e com suas mais distintas peculiaridades, fossem satisfeitos de modo tempestivo, adequado e eficaz. ${ }^{28}$

Considerando que as normas trabalhistas de direito material, assim como outros direitos sociais, são fruto do paradigma político do Estado Social, é certo que a aplicação do modelo processual típico do positivismo liberalista acabaria por esvaziar sua finalidade protecionista e inviabilizar sua adequada concretização. Para suprir o distanciamento entre os direitos fundamentais idealmente consagrados e os recursos processuais até então disponíveis, o Direito Processual assumiu a função instrumentalista ou teleológica, passando a ser visto como um conjunto ético de ações tendentes a promover o acesso à ordem jurídica justa. ${ }^{29}$

A ordem constitucional vigente empenha-se na realização da justiça substancial, garantindo meios adequados e efetivos de satisfação tempestiva dos direitos materiais. A superação das defasagens do processo clássico faz-se por meio da implementação das tutelas diferenciadas - por exemplo, as tutelas antecipada, específica, inibitória e metaindividual.

\footnotetext{
${ }^{28}$ PIMENTA, José Roberto Freire; PORTO, Lorena Vasconcelos. Instrumentalismo substancial e tutela jurisdicional civil e trabalhista: uma abordagem histórico-jurídica. Revista do TRT da $3^{\text {a }}$ Região, Belo Horizonte, v. 43, n. 73, p. 85-122, junho 2006.

${ }^{29}$ SOUTO MAIOR, Jorge Luiz. A efetividade do processo. In: SOUTO MAIOR, Jorge Luiz; CORREIA, Marcus Orione Gonçalves (Org.). Curso de Direito do Trabalho - Vol. 4: direito processual do trabalho. São Paulo: LTr, 2009. p. 46.
} 
As técnicas de sumarização contidas nas tutelas cautelar e antecipada, que superam o padrão uniformizado no procedimento ordinário de cognição exauriente, visam a eliminar a defasagem quanto à duração do processo. Minimizam o distanciamento entre o momento em que o direito deveria ter sido usufruído pelo titular e o momento em que o provimento jurisdicional é realizado. ${ }^{30}$

A tutela específica abandona a conformação uniforme da tutela ressarcitória e visa a sanar a defasagem quanto ao objeto do processo, eliminando o distanciamento entre o que é prometido pelo direito material e o que é obtido por meio do processo ${ }^{31}$. A necessidade de proteção a direitos fundamentais extrapatrimoniais faz com que se priorize o cumprimento in natura da obrigação e exige que a prestação jurisdicional seja prestada em tempo razoável.

Se o direito demandado em juízo é extrapatrimonial, sua conversão em perdas e danos acaba por beneficiar o devedor inadimplente e consagra no ordenamento a prática da expropriação do direito fundamental. ${ }^{32}$ Diante da insuficiência da tutela ressarcitória, a tutela específica representa a quebra do dogma liberal da intangibilidade da vontade do devedor, pois atua na esfera privada do réu, para obrigá-lo a cumprir determinada obrigação, fazendo uso, se necessário, de medidas coercitivas.

Em nosso ordenamento, a tutela específica foi inserida de forma isolada, em dispositivos reservados como os da Lei de Ação Civil Pública (LACP, Lei 7.347/85, artigo 11) e do Código de Defesa do Consumidor (CDC, Lei 8.078/90, artigo 84). Posteriormente, a regra foi generalizada nos artigos 461 e 461-A do Código de Processo Civil (CPC).

A decisão judicial que concede a tutela específica tem caráter mandamental ou executiva lato $s e n s u^{33}$. O juiz fixa ao réu prazo para o

\footnotetext{
${ }^{30}$ PIMENTA, José Roberto Freire; PORTO, Lorena Vasconcelos. Instrumentalismo substancial e tutela jurisdicional civil e trabalhista: uma abordagem histórico-jurídica. Revista

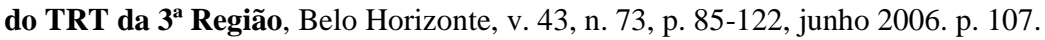

${ }^{31}$ Não é outra a lição que se extrai do tutto quello e proprio quello de Chiovenda: "o processo deve dar a quem tem direito, tanto quanto seja praticamente possível, tudo aquilo e exatamente aquilo que ele tem o direito de conseguir" (apud DINAMARCO, 2009, p. 319320).

32 DINAMARCO, Cândido Rangel. A instrumentalidade do processo. 14. ed. (rev., atual.). São Paulo: Malheiros, 2009. p. 354.

${ }^{33}$ Dinamarco (2002, p. 230-231) explica que: “A mandamentalidade é uma eficácia, que certas sentenças têm, de mandar o sujeito desenvolver determinada conduta, não se limitando a declarar um direito, constituir uma situação jurídica nova ou a condenar, autorizando a instauração do processo executivo. O que valoriza a sentença mandamental, em sua
} 
adimplemento da obrigação e comina, para o caso de descumprimento da decisão, a aplicação de multa diária (astreinte) ou outra medida coercitiva a ser instituída conforme a necessidade e a conveniência do caso concreto $^{34}$. As medidas de coerção (ou de execução indireta) contidas no preceito cominatório atuam sobre a vontade do devedor, procurando persuadir o renitente a adimplir.

Além das medidas coercitivas, o juiz ainda pode se valer das medidas sub-rogatórias, a exemplo da busca e apreensão, da remoção de pessoas ou coisas, da interdição de estabelecimento, da paralisação de atividade nociva e outras. Por meio dessas medidas, o Estado-juiz se subroga no papel do devedor para atingir seu patrimônio e fazer valer o provimento, independentemente do concurso da vontade do condenado. As medidas de sub-rogação (ou de execução direta) suprem o inadimplemento do devedor, satisfazendo o credor sem qualquer colaboração do obrigado. ${ }^{35}$

Nessa perspectiva, fica evidente a opção da lei processual pela prioridade jurídica da tutela específica. A esse respeito, é exaustiva a lição de Barbosa Moreira:

Não há dúvida de que a tutela específica é superior e deve ser preferida, sempre que possível, a qualquer outra forma. O que o ordenamento jurídico quer é que os deveres e obrigações se cumpram tais quais são. Se a alguém é dado pretender, segundo o direito, que outrem se abstenha de algo, há de poder contar com o direito para conseguir a utilidade que espera da abstenção - essa utilidade, e não outra, "equivalente" que seja, ou inculcada como tal. E a necessidade de

capacidade de promover a efetivação dos direitos, é a imediatidade entre seu momento de eficácia e a execução." O autor complementa: "O sistema repele, todavia, a existência de sentenças que sejam somente mandamentais, sem serem condenatórias. O mandamento, ou comando a ter determinada conduta, é em alguns casos acrescido à eficácia de condenação, mas sem excluí-la. Existem portanto sentenças condenatórias puras e sentenças condenatórias mandamentais; e a eficácia de comando, ou mandamento, é acrescida pela lei nos casos em que o legislador entende conveniente, com o objetivo de promover com mais rapidez e agilidade a efetivação do preceito contido em sentença."

${ }^{34}$ Importantes características em prol da efetividade da ordem judicial são a atipicidade e a plasticidade dos meios executivos, que permitem ao juiz escolher e determinar, de ofício ou a requerimento do credor, o meio mais adequado à satisfação do direito, ainda que não expressamente previsto em lei (PIMENTA, 1999, p. 42).

${ }^{35}$ MOREIRA, José Carlos Barbosa. Temas de Direito Processual: segunda série. 2. ed. São Paulo: Saraiva, 1988. p. 224. 
recorrer às vias judiciais para obter proteção nada altera, em princípio, no quadro: se o processo constitui instrumento para a realização do direito material, só se pode a rigor considerar plenamente eficaz a sua atuação quando ele se mostre capaz de produzir resultado igual ao que se produziria se o direito material fosse espontaneamente observado. ${ }^{36}$

No sistema da tutela específica, é natural que a conversão em perdas e danos ocupe o último lugar na preferência do legislador. Por isso é que, de acordo com o artigo 461, $\S 1^{\circ}$, do CPC, essa solução de "meiajustiça" somente pode ser imposta ao credor quando não for possível obter o resultado final desejado sequer mediante atuação das providências referidas no caput - ou, ainda, quando o próprio credor fizer opção válida pela conversão. ${ }^{37}$

$\mathrm{Na}$ tutela do direito à saúde do trabalhador, a conduta prevencionista deve prevalecer sobre o padrão centrado no pagamento de adicionais remuneratórios e indenizações - que, em última análise, representa a venda da saúde do trabalhador. ${ }^{38}$

Não se ignora que o artigo $7^{\circ}$ da $\mathrm{CR} / 88$, em seu inciso XXIII, expressamente institui o pagamento do "adicional de remuneração para as atividades penosas, insalubres ou perigosas". Tal dispositivo, porém, não pode ser interpretado como uma autorização para, em pagando o adicional, desvencilhar-se o empregador da obrigação de sempre atuar rumo à eliminação dos riscos ambientais. ${ }^{39}$

Os adicionais remuneratórios não são previstos para que se perpetuem na prática do contrato, mas para que onerem a mão de obra e, assim, convençam o empregador a providenciar a eliminação ou a neutralização das condições de trabalho que ensejam seu pagamento. ${ }^{40}$

Assim, a previsão de pagamento do adicional somente pode ser

\footnotetext{
${ }^{36}$ MOREIRA, José Carlos Barbosa. Temas de Direito Processual: segunda série. 2. ed. São Paulo: Saraiva, 1988.

${ }^{37}$ DINAMARCO, Cândido Rangel. A reforma da reforma. 4. ed. (rev., atual.), 2. tir. São Paulo: Malheiros, 2002. p. 233.

38 OLIVEIRA, Sebastião Geraldo de. Proteção jurídica à saúde do trabalhador. 5. ed. (rev., atual. e ampl.). São Paulo: LTr, 2010. p. 130.

${ }^{39}$ ANDRADE, Laura Martins Maia de. Meio ambiente do trabalho e ação civil pública trabalhista. São Paulo: Juarez de Oliveira, 2003. p. 55.

${ }^{40}$ MELO, Raimundo Simão de. Direito ambiental do trabalho e a saúde do trabalhador. 4. ed. São Paulo: LTr, 2010. p. 191.
} 
compreendida em cotejo com o inciso XXII do mesmo artigo $7^{\circ}$, que fixa, como direito do trabalhador, a redução dos riscos inerentes ao trabalho. "O empregado mais consciente não quer adicionais compensatórios para expor sua vida e saúde a perigo; ao contrário, prefere o ambiente de trabalho saudável, conforme lhe asseguram as normas jurídicas". ${ }^{41}$

Sendo essa a correta base de interpretação da promessa jurídica de proteção à saúde do trabalhador e ao meio ambiente de trabalho saudável, a efetividade do direito material depende da adoção de instrumentos processuais hábeis a garantir o cumprimento das obrigações "tais quais são". ${ }^{42}$ Destaca-se, desse modo, a importância do sistema da tutela específica das obrigações de fazer como meio de implementação da redução dos riscos ambientais. ${ }^{43}$

Oliveira expõe um rol exemplificativo de obrigações de fazer cujo cumprimento pode ser pleiteado na defesa da redução dos riscos ambientais, tais como: adequar o ambiente de trabalho às condições de salubridade; impedir o prosseguimento de atividade nociva ou perigosa; fornecer equipamento de segurança e proteção adequados; ministrar instruções sobre as normas de segurança; implantar e colocar em funcionamento a CIPA, o SESMT e o PCMSO; elaborar e implementar o PPRA; adequar o mobiliário às normas de ergonomia; conceder intervalo de 10 minutos a cada 50 minutos trabalhados nas atividades de entradas de dados, etc. ${ }^{44}$

É sempre dada ao trabalhador a possibilidade de ajuizar reclamação trabalhista para pedir a condenação do empregador ou tomador de serviços em alguma obrigação de fazer ou não fazer atinente às

${ }^{41}$ OLIVEIRA, Sebastião Geraldo de. Proteção jurídica à saúde do trabalhador. 5. ed. (rev., atual. e ampl.). São Paulo: LTr, 2010. p. 435.

${ }^{42}$ MOREIRA, José Carlos Barbosa. Temas de Direito Processual: segunda série. 2. ed. São Paulo: Saraiva, 1988. p. 31.

${ }^{43}$ Para a aplicação subsidiária das regras do CPC no Processo do Trabalho, o fundamento está na releitura do artigo 769 da CLT. Segundo Chaves (2007, p. 84), a expressão "omissão" merece ser examinada à luz das modernas teorias das lacunas, de modo a preservar a efetividade e promover a revitalização do Direito Processual do Trabalho, a partir do influxo de novos valores, princípios, técnicas, institutos e ferramentas. A "lacuna jurídica" não se revela apenas na simples omissão normativa, mas também no distanciamento entre o regramento legal e a realidade social, como consequência do transcurso do tempo e do desenvolvimento das circunstâncias e dos valores. Sob essa inspiração, abrem-se as portas do Processo do Trabalho para os efeitos das ondas renovatórias do Processo Civil, substituindo normas processuais trabalhistas superadas pelo tempo e pela técnica.

${ }^{44}$ OLIVEIRA, Sebastião Geraldo de. Proteção jurídica à saúde do trabalhador. 5. ed. (rev., atual. e ampl.). São Paulo: LTr, 2010. p. 434. 
condições de saúde, higiene e segurança nos locais de trabalho, inclusive mediante preceito cominatório. No entanto, como observa Oliveira ${ }^{45}$, ações individuais com esse objeto raramente são vistas na Justiça do Trabalho:

E quais as razões dessa inércia? $O$ receio de desemprego ou de retaliações por parte do empregador com certeza inibe as iniciativas dos empregados até mesmo de procurar o sindicato para busca de uma solução. Por outro lado, a condenação nas obrigações de fazer não implica valores patrimoniais, e, com isso, não há estímulos para advogados e sindicatos no patrocínio dessas reclamações. Ademais, o direito à saúde do trabalhador ainda é ignorado pela maioria dos empregados e sindicatos, não entra nos currículos das faculdades de Direito e dispõe de pouca elaboração doutrinária. Acrescente-se o fato de que a doutrina jurídico-trabalhista sempre esteve mais preocupada com a cultura dos adicionais compensatórios e não com a manutenção da saúde do trabalhador com o bem maior a ser tutelado.

Nesse contexto, o manejo da ação civil pública, disciplinada pela Lei $7.347 / 85$ e aperfeiçoada pela CR/88 e pela Lei 8.078/90, tem representado meio mais adequado e eficaz à tutela do direito em questão. Com efeito, a ação civil pública é um instrumento processual de extrema relevância na defesa dos direitos metaindividuais ou coletivos lato sensu (artigo 81, § único, do CDC) - ao lado do mandado de segurança coletivo e da ação popular (artigo $5^{\circ}$, incisos LXX e LXXIII, da CR/88).

Melo afirma que, desde a promulgação da $\mathrm{CR} / 88$, que alterou as funções do Ministério Público, e da Lei Complementar 75/1993, que as regulamentou, vem aumentando o número de ações coletivas no âmbito da Justiça do Trabalho. $\mathrm{O}$ autor relata que são comuns ações civis públicas que buscam o cumprimento de obrigações de fazer ou não fazer relacionadas à observância de normas trabalhistas, mediante multa cominatória, na forma do artigo 11 da LACP. ${ }^{46}$

\footnotetext{
45 Ibidem.

${ }^{46}$ MELO, Raimundo Simão de. Direito ambiental do trabalho e a saúde do trabalhador. 4. ed. São Paulo: LTr, 2010. p. 132.
} 
$\mathrm{Na}$ ação civil pública ambiental, também é viável pedir a interdição de obras, locais de trabalho ou de toda uma empresa, quando a ausência de requisitos mínimos de segurança ou as condições de atividade colocam em risco iminente a saúde e a vida dos trabalhadores ${ }^{47}$. Em casos como tais, as tutelas coletiva, específica e antecipatória se aliam em prol da efetividade - como autoriza o artigo 12 da LACP e os artigos 273 e 461, $\S 3^{\circ}$, do CPC. A tutela específica das obrigações de fazer ou não fazer, por óbvio, não exclui a possibilidade de condenação ao pagamento de indenizações genéricas pelos danos já causados ao meio ambiente do trabalho ou outro interesse metaindividual trabalhista. ${ }^{48}$

\section{CONCLUSÃO}

O ordenamento jurídico brasileiro consagra o direito social fundamental à redução dos riscos inerentes ao trabalho. Do complexo de normas concernentes à saúde do trabalhador, depreende-se a orientação para a implementação, em caráter prioritário, do padrão prevencionista dos riscos ambientais. O objetivo é fazer com que, mediante a promoção de medidas de saúde, higiene e segurança do trabalhado, reduzam-se as ocorrências de acidentes e doenças ocupacionais.

Esse objetivo deve repercutir no modo como se pratica a tutela jurisdicional. Se o valor máximo do ordenamento jurídico está centrado na dignidade da pessoa humana e se a preservação da saúde apresenta-se como elemento essencial de promoção da vida digna, está claro que o processo, como instrumento ético e deontológico que é, não pode permanecer alheio à opção axiológica da nação.

As ações em que se pleiteia o pagamento de adicionais remuneratórios e indenizações têm cunho meramente ressarcitório e não atendem propriamente à promessa legal de proteção e promoção da saúde. O ideal é que, a esse padrão ressarcitório, os sindicatos e o Ministério

\footnotetext{
${ }^{47}$ A possibilidade de interdição é prevista no artigo 161 da CLT: “Art. 161 - O Delegado Regional do Trabalho, à vista do laudo técnico do serviço competente que demonstre grave e iminente risco para o trabalhador, poderá interditar estabelecimento, setor de serviço, máquina ou equipamento, ou embargar obra, indicando na decisão, tomada com a brevidade que a ocorrência exigir, as providências que deverão ser adotadas para prevenção de infortúnios de trabalho."

${ }^{48}$ MELO, Raimundo Simão de. Direito ambiental do trabalho e a saúde do trabalhador. 4. ed. São Paulo: LTr, 2010. p. 133.
} 
Público do Trabalho aliem ações em que busquem o cumprimento específico das normas de proteção.

O regramento processual - especialmente o sistema disposto no artigo 11 da Lei 7.347/85 e no artigo 461 do CPC - viabiliza que os legitimados acessem o Poder Judiciário e, pleiteando o cumprimento específico das obrigações de fazer voltadas à prevenção e à redução dos riscos ambientais, obtenham provimento adequado e efetivo.

\section{REFERÊNCIAS BIBLIOGRÁFICAS}

ANDRADE, Laura Martins Maia de. Meio ambiente do trabalho e ação civil pública trabalhista. São Paulo: Juarez de Oliveira, 2003.

BARROSO, Luís Roberto. $O$ direito constitucional e a efetividade de suas normas: limites e possibilidades da Constituição brasileira. 9. ed. Rio de Janeiro: Renovar, 2009.

CHAVES, Luciano Athayde. As lacunas no direito processual do trabalho. In: CHAVES, Luciano Athayde (Org.). Direito processual do trabalho: reforma e efetividade. São Paulo: LTr, 2007, p. 52-96.

COMPARATO, Fábio Konder. Afirmação histórica dos direitos humanos. 2. ed. (rev. e ampl.). São Paulo: Saraiva, 2001.

DINAMARCO, Cândido Rangel. A instrumentalidade do processo. 14. ed. (rev., atual.). São Paulo: Malheiros, 2009.

A reforma da reforma. 4. ed. (rev., atual.), 2. tir. São Paulo: Malheiros, 2002.

FERREIRA FILHO, Manoel Gonçalves. Direitos humanos fundamentais. 11. ed. (rev. e aum.). São Paulo: Saraiva, 2009.

MAGALHÃES, José Luiz Quadros de. Direitos humanos: sua história, sua garantia e a questão da indivisibilidade. São Paulo: J. de Oliveira, 2000.

MELO, Raimundo Simão de. Direito ambiental do trabalho e a saúde do trabalhador. 4. ed. São Paulo: LTr, 2010.

MORAES, Alexandre de. Direitos humanos fundamentais. 2. ed. São Paulo: Atlas, 1998.

MORAES, Maria Celina Bodin de. O conceito de dignidade humana: substrato axiológico e conteúdo normativo. In: SARLET, Ingo Wolfgang (Org.). Constituição, direitos fundamentais e direito privado. 2. ed. Porto Alegre: Livraria do Advogado, 2006, p. 107-149. 
MOREIRA, José Carlos Barbosa. Temas de Direito Processual: segunda série. 2. ed. São Paulo: Saraiva, 1988.

OLIVEIRA, Sebastião Geraldo de. Indenizações por acidente do trabalho ou doença ocupacional. 5. ed. (rev., ampl. e atual.). São Paulo: LTr, 2009.

Proteção jurídica à saúde do trabalhador. 5. ed. (rev., atual. e ampl.). São Paulo: LTr, 2010.

PIMENTA, José Roberto Freire. A prisão como meio de efetivação da tutela específica e antecipada das obrigações de fazer e não fazer no Processo do Trabalho. Revista Genesis - Revista de Direito do Trabalho, Curitiba, v. 13, n. 73, p. 37-68, janeiro 1999.

; PORTO, Lorena Vasconcelos. Instrumentalismo substancial e tutela jurisdicional civil e trabalhista: uma abordagem histórico-jurídica. Revista do TRT da $3^{\text {a }}$ Região, Belo Horizonte, v. 43, n. 73, p. 85-122, junho 2006.

SAAD, E. Gabriel. Curso de Direito do Trabalho. São Paulo: LTr, 2000. SARLET, Ingo Wolfgang. Mínimo existencial e direito privado: apontamentos sobre algumas dimensões da possível eficácia dos direitos fundamentais sociais no âmbito das relações jurídico-privadas. In: NETO, Cláudia Pereira de Souza; SARMENTO, Daniel (Org.). A Constitucionalização do Direito. Rio de Janeiro: Ed. Lumen Júris, 2007, p. 321- 354.

SUSSEKIND, Arnaldo. Instituições de Direito do Trabalho. Vol. II. 22. ed. (atual. por Arnaldo Sussekind e João de Lima Teixeira Filho). São Paulo: LTr, 2005.

SOUTO MAIOR, Jorge Luiz. A efetividade do processo. In: SOUTO MAIOR, Jorge Luiz; CORREIA, Marcus Orione Gonçalves (Org.). Curso de Direito do Trabalho - Vol. 4: direito processual do trabalho. São Paulo: LTr, 2009. 